[Contribution from the Chemical Laboratory of the University of Michigan]

\title{
THE SEPARATION AND DETERMINATION OF COBALT. III. THE VOLUMETRIC DETERMINATION OF COBALT ${ }^{1}$
}

By H. H. WILIARd aNd DÓROTHY HALL

Received July 24, 1922

All of the volumetric methods for cobalt which have any claim to accuracy may be divided into two classes. In the first class the cobalt is oxidized to the trihydroxide by adding standard permanganate solution in the presence of a neutralizing agent, such as zinc oxide or mercuric oxide. The permanganate may be added in excess and the latter titrated with a suitable reducing agent. ${ }^{2}$ The results obtained are only fairly good at best. In the second class the cobalt is oxidized to the trivalent form, (the trihydroxide, an amine or a compound with potassium hydrogen carbonate) by means of hydrogen peroxide, ${ }^{3}$ hypochlorite, ${ }^{4}$ bromine $^{5}$ or iodine. ${ }^{6}$ After removing the excess of oxidizing agent, usually by filtering off the cobaltic hydroxide, the cobalt is reduced in acid solution to a cobaltous salt by means of standard ferrous sulfate or by potassium iodide, the iodine being titrated with thiosulfate solution. The composition of the oxide obtained by these different methods appears to vary considerably. Of the various oxidizing agents suggested, only iodine and hydrogen peroxide do not oxidize nickel; the excess of peroxide is easily removed by boiling, and an oxide of the theoretical composition is obtained without the necessity of a troublesome filtration; therefore, all other oxidizing agents were finally discarded by us. The use of hydrogen peroxide in a bicarbonate solution, as suggested by Job ${ }^{3 g}$, will be taken up later.

A few methods have been suggested, based upon the precipitation of cobalt as cyanide, ${ }^{7}$ ferrocyanide, ${ }^{8}$ or cobaltinitrite, ${ }^{9}$ but these are very empirical and of comparatively little value. The alkalimetric titration of

${ }^{1}$ From a dissertation presented by Dorothy Hall in partial fulfilment of the requirements for the degree of Doctor of Philosophy.

${ }^{2}$ Winkler, $Z$. anal. Chem., 3, 265, 420 (1864). von Reis, $Z$. angew. Chem., 3, 695 (1890). Harris, This Journal, 20, 173 (1898).

(a) McCulloch, Chem. Nerws, 56, 27 (1887). (b) Fischer, Berg. Hitttenm. Ztg., 47, 453 (1888). (c) Carnot, Compt. rend., 108, 610 (1889). (d) Moore, Chem. News, 82, 73 (1900). (e) Metz1, Z. anal. Chem., 53, 537 (1914). (f) Engle and Gustavson, $J$. Ind. Eng. Chem, 8, 901 (1916). (g) Job, Ann. chim. phys., 20, 214 (1900). (1870)

${ }^{4}$ (a) Bayley, Chem. News, 39, 81 (1879). (b) Fleischer, J. prakt. Chem., 110, 48

${ }^{5}$ Ref. 3d. Taylor, Chem. News, 87, 201 (1903).

${ }^{6}$ Donath, Ber., 12, 1868 (1879).

'McCulloch, Chem. News, 59, 51 (1889). Rupp and Pfenning, Chem.-Ztg., 34, 322 (1910). Johnson, "Chemical Analysis of Special Steels," John Wiley and Sons, 1920, 3d. Ed., p. 376.

${ }^{8}$ Jamieson, This Journal, 32, 757 (1910).

${ }^{3}$ Karlslake, J. anal. Chem., 6, 469 (1892). 
cobalt-ammonium orthophosphate, $\mathrm{CoNH}_{4} \mathrm{PO}_{4}$, has also been suggested, ${ }^{10}$ but this is subject to the errors mentioned in a previous paper (p. 2230). Metz $^{3 e}$ was the first to give the details of a really accurate procedure involving the oxidation of cobalt to cobaltic hydroxide. He used two methods; in the first, hydrogen peroxide was added to a solution containing sodium bicarbonate and the green compound formed was decomposed by boiling with excess of sodium hydroxide, forming cobaltic hydroxide. In the second method, an ammoniacal solution of cobalt containing ammonium chloride was oxidized to a cobaltic amine by hydrogen peroxide. When this was boiled with excess of sodium hydroxide until all ammonia was expelled the amine was decomposed, forming cobaltic hydroxide. The first method is simpler and shorter. Nickel is not oxidized under these conditions. The excess of peroxide was destroyed by boiling, potassium iodide was added, the solution strongly acidified with sulfuric acid and when the precipitate had dissolved, the liberated iodine was titrated with thiosulfate solution. Excellent results were obtained in the presence of various amounts of nickel.

Engle and Gustavson ${ }^{3 f}$ used sodium perborate instead of hydrogen peroxide, and omitted the bicarbonate, adding directly an excess of sodium hydroxide. The excess of perborate was more readily destroyed than was peroxide, only 10 minutes' boiling being required. The subsequent operations were the same.

\section{Oxidation to Cobaltic Hydroxide}

Iodide as a Reducing Agent.-The method of Engle and Gustavson was first tried. The reaction is represented by the following equations.

$$
\begin{aligned}
& 8 \mathrm{CoSO}_{4}+4 \mathrm{NaBO}_{3}+14 \mathrm{NaOH}+5 \mathrm{H}_{2} \mathrm{O}=8 \mathrm{Co}(\mathrm{OH})_{3}+\mathrm{Na}_{2} \mathrm{~B}_{4} \mathrm{O}_{7}+8 \mathrm{Na}_{2} \mathrm{SO}_{4} \\
& 2 \mathrm{CO}(\mathrm{OH})_{3}+2 \mathrm{KI}+3 \mathrm{H}_{2} \mathrm{SO}_{4}=2 \mathrm{COSO}_{4}+2 \mathrm{I}+6 \mathrm{H}_{2} \mathrm{O}+\mathrm{K}_{2} \mathrm{SO}_{4} \\
& 2 \mathrm{I}+2 \mathrm{Na}_{2} \mathrm{~S}_{2} \mathrm{O}_{3}=2 \mathrm{NaI}+\mathrm{Na}_{2} \mathrm{~S}_{4} \mathrm{O}_{6}
\end{aligned}
$$

Samples of metallic cobalt were dissolved in sulfuric acid, part of the latter was neutralized, $1 \mathrm{~g}$. of sodium perborate was added, and then an excess of $3 \mathrm{~g}$. of sodium hydroxide over that required to neutralize the solution. The solution in an Erlenmeyer flask was boiled for 10 minutes and cooled, carbon dioxide being passed through to expel the air. Two $\mathrm{g}$. of potassium iodide was added, followed by $100 \mathrm{cc}$. of dil. sulfuric acid ( 1 of acid to 4 of water), making a total volume of $200 \mathrm{cc}$. The flask was stoppered and allowed to stand until the solution was clear, after which the iodine formed was titrated with $0.025 \mathrm{~N}$ thiosulfate solution standardized against pure potassium dichromate solution. The end-point was permanent in an atmosphere of carbon dioxide, even after standing for several hours.

A point not mentioned in previous work on this subject is the length of time required for the cobaltic hydroxide to dissolve, which varied from half an hour with small amounts to 2 hours with large amounts. This detracts considerably from the value of the method, since unless an atmos-

${ }^{10}$ Dakin, Z. anal. Chem., 41, 279 (1902). Schoeller and Powell, Analyst, 41, 124 (1916); J. Iron Steel Inst., 97, 445 (1918). 
phere free from oxygen is used this long exposure of the acid iodide solution causes the liberation of a slight excess of iodine.

A $10 \%$ stock solution of potassium iodide was prepared with water which had been boiled and cooled in an atmosphere of hydrogen. Blanks were run as follows.

A solution containing $200 \mathrm{cc}$. of water and $30 \mathrm{cc}$. of $10 \%$ sodium hydroxide was boiled for 10 minutes while carbon dioxide was passed through it and it was cooled; 20 cc. of potassium iodide solution was added, then $100 \mathrm{cc}$, of $1: 3$ sulfuric acid and the flask kept stoppered for 2 hours. The liberated iodine required $0.19-0.21 \mathrm{cc}$. of $0.025 \mathrm{~N}$ sodium thiosulfate solution, and accordingly a correction of $0.20 \mathrm{cc}$. was deducted in all titrations in which this solution was used. Later, another stock solution was prepared having a blank of $0.12 \mathrm{cc}$. It is possible that impurities in the sodium hydroxide may account for part of this blank.

In 30 determinations in which the weights of cobalt varied from 26 to $56 \mathrm{mg}$. the error varied from +0.2 to $-0.8 \mathrm{mg}$., with an average of -0.2 $\mathrm{mg}$.

Cobalt Determined After Precipitation with Phenyl-thiohydantoic Acid.-Samples of cobalt were dissolved in nitric acid, the solutions

TABLE I

\begin{tabular}{|c|c|c|c|c|}
\hline Expt. & $\begin{array}{c}\text { Co taken } \\
\text { G. }\end{array}$ & $\begin{array}{c}0.025 \mathrm{~N} \mathrm{Na} \mathrm{N}_{2} \mathrm{O}_{3} \\
\text { Corrected } \\
\text { Ce. }\end{array}$ & $\begin{array}{l}\text { Co found } \\
\text { G. }\end{array}$ & $\begin{array}{l}\text { Error } \\
\mathrm{Mg} .\end{array}$ \\
\hline 1 & 0.0201 & 13.73 & 0.0202 & +0.1 \\
\hline 2 & 0.0204 & 14.01 & 0.0206 & +0.2 \\
\hline 3 & 0.0310 & 21.12 & 0.0311 & +0.1 \\
\hline 4 & 0.0237 & 16.20 & 0.0240 & +0.3 \\
\hline 5 & 0.0215 & 14.68 & 0.0216 & +0.1 \\
\hline 6 & 0.0205 & 14.38 & 0.0201 & -0.4 \\
\hline 7 & 0.0294 & 20.14 & 0.0296 & +0.2 \\
\hline 8 & 0.0214 & 14.79 & 0.0218 & +0.4 \\
\hline 9 & 0.0248 & 17.03 & 0.0251 & +0.3 \\
\hline 10 & 0.0331 & 22.73 & 0.0335 & +0.4 \\
\hline 11 & 0.0262 & 17.87 & 0.0263 & +0.1 \\
\hline 12 & 0.0370 & 25.55 & 0.0376 & +0.6 \\
\hline 13 & 0.0278 & 19.05 & 0.0280 & +0.2 \\
\hline 14 & 0.0287 & 19.74 & 0.0290 & +0.3 \\
\hline 15 & 0.0255 & 17.34 & 0.0255 & 0 \\
\hline 16 & 0.0356 & 24.26 & 0.0356 & 0 \\
\hline
\end{tabular}

made ammoniacal, diluted to $200 \mathrm{cc}$, and the cobalt was precipitated with phenyl-thiohydantoic acid as previously described. ${ }^{11}$ In the first 10 experiments the precipitate was removed from the filter paper and dissolved in $20 \mathrm{cc}$. of conc. hydrochloric acid and $50 \mathrm{cc}$. of conc. nitric acid. This had to be done carefully, as the oxidation of the carbonaceous matter

$"$ This JOURNaL, 44, 2221 (1922). 
was rather violent. The precipitate adhering to the filter paper was burned, dissolved in perchloric acid, and added to the main solution. Ten cc. of conc. sulfuric acid was added and, after evaporation of the solution to the appearance of fumes, sodium perborate was added and the determination carried out as previously described. In the last 6 experiments a more rapid and convenient procedure was adopted. The cobalt precipitate was dried and ignited to oxide. This oxide was then fused with potassium hydrogen sulfate and dissolved in water. A porcelain crucible was preferred to one of platinum, since, if the fusion was made in platinum, it was necessary to apply a blank correction for the amount of iron invariably extracted. In Expts. 15 and 16 a platinum crucible was used and a correction of $0.45 \mathrm{cc}$. of thiosulfate was applied. That the results are satisfactory is shown in Table I. The cobalt must be free from all metals which would be oxidized by hydrogen peroxide in alkaline solution and would thus affect the iodide titration. Attempts made to eliminate the oxidizing effect of iron upon the potassium iodide titration by the addition of fluoride or phosphate were unsuccessful. This metal must, therefore, be absent. The presence of nickel is entirely with. out effect.

Ferrous Sulfate as a Reducing Agent.--McCulloch ${ }^{3 a}$ and Fleischer ${ }^{\text {it }}$ used ferrous sulfate as a reducing agent, adding it to the strongly alkaline solution, acidifying and titrating the excess of ferrous iron with potassium permanganate or potassium dichromate solution. This method was tested by us but the results were always too low. After cooling, the cobaltic hydroxide solution was added to an excess of standard ferrous sulfate already acidified with 1:4 sulfuric acid. When ferrous sulfate is added to the alkaline solution, oxidation occurs and the results are too high. In most cases it required half an hour or longer to dissolve all the cobaltic hydroxide. The excess of ferrous sulfate was then titrated with permanganate or dichromate solution. With dichromate, ferricyanide was used as an external indicator; with permanganate, it was necessary to add nickel sulfate to eliminate the pink cobalt color; this is, however, unsatisfactory when more than $0.08 \mathrm{~g}$. of cobalt is present.

The ferrous sulfate solution was standardized against the dichromate or permanganate solution. It was difficult to dissolve the last trace of cobaltic hydroxide. Heating facilitated solution, but in this case an atmosphere of carbon dioxide was required. If an empirical factor is employed, the results are quite satisfactory, as shown in Table II. The average factor calculated from Expts. 1-8 in which the excess was titrated with dichromate is 1.0475 ; from Expts. $9-13$, in which permanganate was used, it is 1.0403 . When these values are applied the error as shown in the last column becomes negligible in nearly every case. Although there is a loss of oxygen, indicating that ferrous sulfate is too weak a reducing 
agent, this loss is remarkably constant and apparently varies directly with the amount of cobalt.

TABLE II

Ferrous Sulfate as Reducing Agent

$\begin{array}{cccccc}\text { Expt. } & \text { Co taken } & 0.05 \mathrm{~N} \mathrm{FeSO}_{4} & \text { Co found } & \text { Error } & \begin{array}{c}\text { Error with } \\ \text { empirical } \\ \text { factor } \\ \text { Gg. }\end{array} \\ & \text { G. } & \text { Cc. } & \text { G. } & \text { Mg. } & 0 \\ 1 & 0.0582 & 18.84 & 0.0555 & -2.7 & 0 \\ 2 & 0.0462 & 14.96 & 0.0441 & -2.1 & 0 \\ 3 & 0.0565 & 18.29 & 0.0539 & -2.6 & 0 \\ 4 & 0.0481 & 15.57 & 0.0459 & -2.2 & 0 \\ 5 & 0.0457 & 14.79 & 0.0436 & -2.1 & 0 \\ 6 & 0.0435 & 14.08 & 0.0415 & -2.0 & 0 \\ 7 & 0.0426 & 13.82 & 0.0407 & -1.9 & +0.1 \\ 8 & 0.0541 & 17.51 & 0.0516 & -2.5 & 0 \\ 9 & 0.0853 & 27.79 & 0.0823 & -3.0 & -0.1 \\ 10 & 0.0530 & 17.28 & 0.0509 & -2.1 & 0 \\ 11 & 0.0322 & 10.44 & 0.0308 & -1.4 & -0.2 \\ 12 & 0.0440 & 14.29 & 0.0421 & -1.9 & -0.2 \\ 13 & 0.0624 & 20.55 & 0.0606 & -1.8 & +0.6\end{array}$

One great advantage in the use of ferrous sulfate is that the presence of ferric iron does not interfere as it does with iodide, and as has been previously mentioned, traces of iron usually contaminate the cobalt when the latter is separated by phenyl-thiohydantoic acid. The reducing action of sodium arsenite, antimony trichloride, potassium thiocyanate and hydrazine salts was found to be very similar to that shown above, all the results being too low.

Stannous Chloride as a Reducing Agent.-Stannous chloride was found to be an admirable reducing agent. The reaction may be expressed by the following equation.

$$
2 \mathrm{Co}(\mathrm{OH})_{3}+\mathrm{SnCl}_{2}+6 \mathrm{HCl}=2 \mathrm{CoCl}_{2}+\mathrm{SnCl}_{4}+6 \mathrm{H}_{2} \mathrm{O} \text {. }
$$

The reduction is immediate and although any ferric iron present is reduced by the stannous chloride it is possible to titrate the excess of the latter by a reagent which also oxidizes the ferrous chloride formed. An atmosphere of carbon dioxide is absolutely necessary and the solution must be acidified as soon as an excess of the reducing agent has been added. The best results were obtained when the standard stannous chloride was made up with fairly concentrated hydrochloric acid so that every $30 \mathrm{cc}$. of stannous chloride contained $15 \mathrm{cc}$. of conc. hydrochloric acid. This left an excess of about $10 \mathrm{cc}$. of acid for each titration.

The excess of stannous chloride was titrated with several oxidizing agents. Iodine was found to be an excellent one on account of the sharpness of the end-point, but it had the disadvantage of requiring a special procedure when iron was present, unless a correction was applied for the 
amount of iron reduced, which is usually unknown. Potassium bromate, potassium iodate and potassium dichromate all gave satisfactory results and will be separately discussed.

Titration of Excess of Stannous Chloride by Iodine.-Cobalt was oxidized in alkaline solution, as previously described, in a $500 \mathrm{cc}$. flask provided with a side tube extending to the bottom. The total volume was kept at about $150 \mathrm{cc}$. After boiling to remove the excess of oxidizing agent the solution was cooled while carbon dioxide was passed through it, and the strongly acid standard solution of stannous chloride added: The solution cleared immediately, giving a pink solution of cobalt chloride. The excess of stannous chloride was then determined with standard iodine, potassium bromate or iodate, potassium iodide being added in the latter cases so that the usual iodine end-point was obtained. The results are shown in Table III. The average error is $0 \mathrm{mg}$.

TABLE III

Reduction By Stannous Chroride and Titration of Excess Iodimetrically

$\begin{array}{ccccc}\begin{array}{c}0.1 \mathrm{~N} \mathrm{SnCl}_{2} \\ \text { added } \\ \text { G. }\end{array} & \begin{array}{c}0.1 \mathrm{~N} \text { iodine } \\ \text { Cc. }\end{array} & \begin{array}{c}\text { Co found } \\ \text { G. }\end{array} & \begin{array}{c}\text { Etror } \\ \mathrm{Mg} .\end{array} \\ 0.0812 & 23.50 & 9.69 & 0.0813 & +0.1 \\ 0.0686 & 22.10 & 10.47 & 0.0686 & 0 \\ 0.0842 & 24.31 & 10.02 & 0.0842 & 0 \\ 0.0662 & 21.97 & 10.74 & 0.0662 & 0 \\ 0.0575 & 21.24 & 11.45 & 0.0576 & +0.1 \\ 0.0457 & 19.47 & 11.76 & 0.0455 & -0.2 \\ 0.0694 & 23.58 & 11.83 & 0.0694 & 0 \\ 0.0704 & 23.49 & 11.45 & 0.0709 & +0.5 \\ 0.0512 & 20.41 & 11.73 & 0.0512 & 0 \\ 0.0576 & 21.88 & 12.05 & 0.0576 & 0 \\ 0.1323 & 33.74 & 11.43 & 0.1316 & -0.7 \\ 0.0883 & 25.93 & 10.96 & 0.0883 & 0 \\ & & \mathrm{KBrO}_{3} & & \\ 0.0757 & 23.42 & 10.67 & 0.0752 & -0.5 \\ 0.0860 & 24.27 & 9.70 & 0.0860 & 0 \\ 0.0701 & 21.50 & 9.50 & 0.0706 & +0.5 \\ & & \mathrm{KIO}_{3} & & \\ 0.0819 & 19.02 & 5.20 & 0.0815 & -0.4 \\ 0.0595 & 19.39 & 9.32 & 0.0594 & -0.1 \\ 0.0458 & 15.39 & 7.55 & 0.0462 & +0.4\end{array}$

In this process, the presence of iron would introduce an error, as it is not re-oxidized by these reagents.

Titration of Excess of Stannous Chloride by Potassium Dichromate.-When the excess of stannotis chloride is oxidized by potassium dichromate solution, the iron which has been reduced by the tin will be oxidized by the dichromate and no error will be introduced. In this method, the cobalt solution was oxidized in the manner described above, and after reduction 
by stannous chloride, an excess of potassium dichromate solution was added. The current of carbon dioxide was then discontinued and the solution was transferred for convenience to a beaker, $30 \mathrm{cc}$. of $5 \mathrm{~N}$ ferric chloride solution was added to increase the delicacy of the end-point and the excess of dichromate was titrated with standard ferrous sulfate; ferri-

\begin{tabular}{|c|c|c|c|c|c|}
\hline & EFFECT & $\begin{array}{r}T \\
I_{R O N} O I\end{array}$ & $\begin{array}{l}\text { E IV } \\
\text { XIDATION }\end{array}$ & СоBALT & \\
\hline & & $0.05 \mathrm{~N}$ & $0.05 N$ & & \\
\hline $\begin{array}{c}\text { Co taken } \\
\text { G. } \\
0.0529\end{array}$ & $\begin{array}{c}\text { Fe added } \\
\mathrm{Mg} . \\
100\end{array}$ & $\begin{array}{c}\mathrm{SnCl}_{2} \\
\mathrm{Cc} . \\
31.85\end{array}$ & $\begin{array}{c}\mathrm{K}_{2} \mathrm{Cr}_{2} \mathrm{O}_{7} \\
\mathrm{Cc} . \\
14.19\end{array}$ & $\begin{array}{c}\text { Co found } \\
\text { G. } \\
0.0520\end{array}$ & $\begin{array}{c}\text { Error } \\
\text { Mg. } \\
-0.9\end{array}$ \\
\hline 0.0522 & 10.0 & 31.85 & 14.38 & 0.0515 & -0.7 \\
\hline 0.0442 & 10.0 & 31.08 & 16.11 & 0.0441 & -0.1 \\
\hline 0.0319 & 10.0 & 25.48 & 15.01 & 0.0309 & -1.0 \\
\hline 0.0660 & 7.0 & 38.22 & 15.86 & 0.0659 & -0.1 \\
\hline 0.0542 & 7.0 & 31.85 & 13.42 & 0.0543 & +0.1 \\
\hline 0.0405 & 7.0 & 25.48 & 11.70 & 0.0406 & +0.1 \\
\hline 0.0640 & 7.0 & 31.87 & 10.16 & 0.0640 & 0 \\
\hline 0.0394 & 7.0 & 25.48 & 12.20 & 0.0391 & -0.3 \\
\hline 0.0469 & 7.0 & 25.54 & 9.51 & 0.0472 & +0.3 \\
\hline 0.0450 & 7.0 & 25.60 & 10.45 & 0.0447 & -0.3 \\
\hline 0.0471 & 5.0 & 38.22 & 22.29 & 0.0470 & -0.1 \\
\hline 0.0405 & 5.0 & 31.85 & 18.18 & 0.0403 & -0.2 \\
\hline 0.0437 & 5.0 & 31.85 & 16.81 & 0.0443 & +0.6 \\
\hline 0.0515 & 5.0 & 31.85 & 14.38 & 0.0515 & 0 \\
\hline 0.0439 & 5.0 & 25.48 & 10.61 & 0.0439 & 0 \\
\hline 0.0352 & 0.0 & 28.80 & 16.85 & 0.0352 & 0 \\
\hline 0.0252 & 0.0 & 28.65 & 20.08 & 0.0252 & 0 \\
\hline 0.0227 & 0.0 & 28.65 & 20.98 & 0.0226 & -0.1 \\
\hline 0.0318 & 0.0 & 28.98 & 18.21 & 0.0317 & -0.1 \\
\hline
\end{tabular}

cyanide was the external indicator. The concentration of hydrochloric acid should not be increased, because this decreases the delicacy of the end-point. If the excess of dichromate should be titrated electrometri-

\section{TABLE V}

Cobalt First Precipitated by Phenyl-Thiohydantoic Acid in Presence of $1 \mathrm{G}$. of IRON

\begin{tabular}{|c|c|c|c|c|}
\hline $\begin{array}{l}\text { Co taken } \\
\text { G. }\end{array}$ & $\begin{array}{c}0.05 \mathrm{~N} \mathrm{SnCl}_{2} \\
\mathrm{Cc} .\end{array}$ & $\underset{\mathrm{Cc} .}{0.05 \mathrm{Cr}_{2} \mathrm{O}_{7}}$ & $\begin{array}{l}\text { Co found } \\
\text { G. }\end{array}$ & $\begin{array}{l}\text { Error } \\
\text { Mg. }\end{array}$ \\
\hline $\begin{array}{l}\text { G. } \\
0.0251\end{array}$ & $\begin{array}{c}\text { Cc. } \\
24.92\end{array}$ & & & $\begin{array}{l}\text { Mg. } \\
+0.1\end{array}$ \\
\hline 0.0286 & 28.65 & 18.94 & 0.0286 & 0 \\
\hline 0.0334 & 28.65 & 17.39 & 0.0332 & -0 \\
\hline 0.0264 & 28.80 & 19.92 & 0.0262 & -0 \\
\hline 0.0227 & 28.65 & 21.04 & 0.0224 & -0 \\
\hline 0.0236 & 28.98 & 21.04 & 0.0234 & -0 \\
\hline 0.0260 & 29.04 & 20.42 & 0.0254 & -0 \\
\hline 0.0232 & 30.01 & 22.36 & 0.0228 & -0 . \\
\hline
\end{tabular}

cally this would become the most rapid and accurate of all volumetric methods for cobalt. The iron was added in the form of ferric alum before the oxidation of the cobalt, and its effect in the latter process is shown in Table IV. 
It is evident that the presence of $10 \mathrm{mg}$. of iron causes incomplete oxidation of the cobalt, while $7 \mathrm{mg}$. has no effect.

Pure cobalt solutions were precipitated by phenyl-thiohydantoic acid in the presence of $1 \mathrm{~g}$. of iron. The precipitate was dried, fused with potassium bisulfate, dissolved in water, oxidized, dissolved in stannous chloride and the excess titrated as above. A single precipitation of cobalt under favorable conditions will carry less than 7 or $8 \mathrm{mg}$. of iron, so that no error is introduced, as is shown in Table V.

Effect of Presence of Copper.--Copper is often associated with cobalt, and unless this element has previously been removed it will precipitate quantitatively with the cobalt upon the addition of phenyl-thiohydantoic acid. Experiments were performed to see what effect copper might have on the oxidation of the cobalt in alkaline solution. Copper does not seem to interfere with the oxidation of the cobalt, but when $13 \mathrm{mg}$. is present the end-point with potassium ferricyanide is difficult to detect, since copper reacts with the indicator. This is evident from the results in Table VI.

TABLE VI

\begin{tabular}{|c|c|c|c|c|c|}
\hline \multicolumn{6}{|c|}{ EFFECT OF COPPER ON OXIDATION OF COBALT } \\
\hline Co taken & $\mathrm{Cu}$ added & $0.05 \mathrm{NSn}$ & $5 \mathrm{~N} \mathrm{~K}_{2}$ & o found & Error \\
\hline G. & Mg. & Cc. & Cc. & G. & $\mathrm{Mg}$. \\
\hline 0.0214 & 5.5 & 28.95 & 21.67 & 0.0214 & 0.0 \\
\hline 0.0250 & 5.5 & 28.95 & 20.34 & 0.0253 & +0.3 \\
\hline 0.0257 & 6.07 & 28.95 & 20.19 & 0.0258 & +0.1 \\
\hline 0.0235 & 6.25 & 24.10 & 16.07 & 0.0237 & +0.2 \\
\hline 0.0208 & 9.2 & 24.10 & 17.07 & 0.0207 & -0.1 \\
\hline 0.0254 & 10.02 & 24.10 & 15.34 & 0.0258 & +0.4 \\
\hline 0.0258 & 13 & 24.10 & 15.16 & 0.0263 & +0.5 \\
\hline 0.0321 & 13.12 & 24.10 & 13.03 & 0.0326 & +0.5 \\
\hline
\end{tabular}

Separation of Iron from Cobalt by means of Zinc Oxide.-The separation of iron from cobalt by precipitation of the former as ferric hydroxide by means of zinc oxide was tested, as it is recommended by certain steel chemists. ${ }^{12}$ The solution, which contained $1 \mathrm{~g}$. of iron, was diluted to a definite volume, allowed to settle, aliquot portions were taken and the cobalt was titrated as above. No account was taken of the volume occupied by the precipitate. The results were invariably several milligrams too low.

Oxidation of Both Stannous and Ferrous Chlorides by Iodine in Neutral Solution.-When cobalt is oxidized in the presence of a little iron, iodine may be used in acid solution to titrate the excess of stannous chloride if a correction is applied for the ferrous chloride formed as previously mentioned (p. 2242), but in a neutral solution in the presence of pyrophosphate the ferrous iron also is oxidized. The latter reaction becomes very slow towards the end, and it is, therefore, necessary to add ${ }^{12}$ Scott, "Standard Methods of Analysis," D. Van Nostrand \& Co., 1920, p. 148. 
excess of iodine and titrate back with thiosulfate solution. On account of the sharpness of the iodine end-point this method is a desirable one.

The concentration of hydrogen ion must be sufficient to prevent any reaction between iodine and hydroxyl ion $\left(P_{\mathrm{H}}\right.$ not over 7.5) and not too great to allow complete reaction with ferrous iron. A solution neutral to aurine $\left(4,4^{\prime}\right.$-dihydroxy-diphenyl-quinomethane), ( $P_{\mathrm{H}}$ about 6.6 ) or barely acid to bromothymol-sulfonephthalein was satisfactory for this purpose.

The cobalt, with $5 \mathrm{mg}$. of iron, was oxidized with perborate in sodium hydroxide solution and reduced by excess of stannous chloride as previously described. This excess was removed by the addition of standard iodine and the slight excess of iodine removed by a drop of thiosulfate solution, the ferrous chloride not being oxidized. Aurine was added, then $5 \mathrm{~g}$. of sodium pyrophosphate crystals and sufficient sodium bicarbonate to change the yellow of the indicator to orange. Iodine in excess was then added and the excess titrated with thiosulfate. This last amount of iodine reacts with the iron reduced by the stannous chloride. The stannous chloride was standardized against the iodine solution and the results were the same whether the acid solution was titrated directly with iodine or whether the stannous salt was added to an alkaline solution containing iron and the above procedure followed.

TABLE VII

Excess of Stannous Chloride in Presence of Iron Titrated Iodimetrically in NeUtrai, Solution

\begin{tabular}{|c|c|c|c|c|c|}
\hline & Co taken & $0.05 N \mathrm{SnC}$ & $05 N$ Iodine & Co found & Error \\
\hline & G. & Cc. & Ce. & G. & $\mathrm{Mg}$. \\
\hline 1 & 0.0475 & 28.35 & 12.30 & 0.0473 & -0.2 \\
\hline 2 & 0.0451 & 28.35 & 13.06 & 0.0451 & 0 \\
\hline 3 & 0.0575 & 28.08 & 8.50 & 0.0577 & +0.2 \\
\hline 4 & 0.0578 & 28.08 & 8.35 & 0.0581 & +0.3 \\
\hline 5 & 0.0430 & 28.08 & 13.44 & 0.0432 & +0.2 \\
\hline 6 & 0.0510 & 28.08 & 10.74 & 0.0511 & +0.1 \\
\hline 7 & 0.0340 & 28.08 & 16.48 & 0.0342 & +0.2 \\
\hline 8 & 0.0308 & 28.08 & 17.47 & 0.0312 & +0.4 \\
\hline 9 & 0.0329 & 27.96 & 16.84 & 0.0328 & -0.1 \\
\hline 10 & 0.0315 & 27.96 & 17.30 & 0.0315 & 0 \\
\hline 11 & 0.0425 & 27.96 & 13.54 & 0.0425 & 0 \\
\hline
\end{tabular}

Since the color change of aurine is influenced somewhat by the pink color of the cobalt and since bromothymol-sulfonephthalein is not blue at this point it seemed desirable to simplify this part of the process by neutralizing the solution after the titration of the excess of stannous chloride. Tetrabromo-phenolsulfonephthalein was used as indicator, since its change to blue is not obscured by the color of the cobalt. If now, 1 to $2 \mathrm{~g}$. of sodium bicarbonate is added, the solution, $150 \mathrm{cc}$. in volume, will be neutral to aurine and ready for the iodine titration. 
The stannous chloride was standardized against the iodine solution under the same conditions. Table VII shows the results obtained. Five mg. of iron was present in all cases. In Expts. 1-8 the solutions were neutralized by the first method, and in $9-11$ by the second.

Stannous Sulfate as a Reducing Agent.-If the excess of reducing agent could be titrated with potassium permanganate solution, the process would be much simplified, but sulfate solutions would then be necessary. A solution of stannous sulfate containing $150 \mathrm{cc}$. of sulfuric acid per liter was made up and standardized against potassium permanganate solution. The stannous sulfate was added to the alkaline solution just as was done with stannous chloride. Results show that it is a much weaker reducing agent than the chloride and, like ferrous sulfate, not powerful enough to retain all the oxygen, the error with $80 \mathrm{mg}$. of cobalt varying from -1.4 to $-2.7 \mathrm{mg}$.

Stannous pyrophosphate in neutral solution was useless as the cobalt precipitate did not dissolve even after long standing unless the solution was strongly acidified.

Titanous Sulfate as a Reducing Agent.-The salts of trivalent titanium are even more powerful reducing agents than stannous chloride and when sulfate solutions are used the excess may be titrated with potassium permanganate, thus eliminating the effect of iron. The reduction of cobaltic hydroxide may be expressed by the following equation.

$$
\mathrm{Ti}_{2}\left(\mathrm{SO}_{4}\right)_{3}+2 \mathrm{Co}(\mathrm{OH})_{3}+3 \mathrm{H}_{2} \mathrm{SO}_{4}=2 \mathrm{Ti}\left(\mathrm{SO}_{4}\right)_{2}+2 \mathrm{COSO}_{4}+6 \mathrm{H}_{2} \mathrm{O} \text {. }
$$

In alkaline solution the reaction, $2 \mathrm{Ti}(\mathrm{OH})_{3}+2 \mathrm{H}_{2} \mathrm{O}=2 \mathrm{Ti}(\mathrm{OH})_{4}+\mathrm{H}_{2}$, occurs, and it is essential that the titanous sulfate be added to a solution which is not strongly alkaline, or that the latter be promptly acidified by the simultaneous addition of acid. To accomplish this purpose 4 methods were used, the cobalt having previously been oxidized in the usual way by perborate in a solution containing $3 \mathrm{~g}$. of sodium hydroxide in a volume of about $100 \mathrm{cc}$. (1) The solution was partly neutralized by passing into it for 15 minutes a rapid current of carbon dioxide; (2) $12 \mathrm{~g}$. of boric acid was added, which is $80 \%$ of the amount required to give a solution neutral to phenolphthalein; $10 \mathrm{~g}$. was too little, $15 \mathrm{~g}$. too much; (3) half the amount of monopotassium orthophosphate required to form a dibasic phosphate was added, but as this had to be followed by a current of carbon dioxide for 15 minutes it offers no advantage over (1) or (2) and is not recommended because it forms a precipitate of titanic phosphate. (4) dil. sulfuric acid was added simultaneously with the titanous sulfate. This gives good results when the acid is added at the proper rate, but on account of the care needed in this operation the method is not recommended.

The titanous sulfate was prepared by the electrolytic reduction of titanic sulfate. An approximately $0.05 \mathrm{~N}$ solution was prepared, containing $150 \mathrm{cc}$. of conc. sulfuric acid per liter. It was stored under a slight pressure of carbon dioxide with no unusual precautions to avoid leakage. The solution oxidized slowly and rather irregularly. 
Just before using, it was standardized against permanganate which, in turn, had been standardizied against sodium oxalate. Whether it was titrated directly against permanganate or added to an alkaline solution previously boiled and cooled in carbon dioxide, the alkali being neutralized by the acid in the standard solution, made no difference. The lavender-colored solution became colorless just before the end-point was reached. It was observed that when the titanous salt was added to a solution sufficiently alkaline to cause slight oxidation, the color of the solution when acidified was a deep amethyst instead of the usual light lavender. All titrations were conducted in an atmosphere'of carbon dioxide.

The results are shown in Table VIII. In Expts. 1-6, Method 1 was used; in 7-10, Method 2; in 11-15, Method 3; and in 16-19, Method 4. Samples of pure cobalt were used in all cases. Experiments in which the cobalt was first precipitated by phenyl-thiohydantoic acid in the presence of $1 \mathrm{~g}$. of iron, and in which Method 4 was used were given in Table II, of Paper I. ${ }^{13}$

TABLE VIII

REDUCED BY TITANOUS SULFATE $0.05 \mathrm{~N} \mathrm{Ti}_{2}\left(\mathrm{SO}_{4}\right)_{3}$

$\begin{array}{rcrrrr} & \text { Co taken } & \text { added } & 0.05 \mathrm{~N} \mathrm{MnO}_{4} & \text { Co found } & \text { Error } \\ & \text { G. } & \text { Cc. } & \text { Cc. } & \text { G. } & \text { Mg. } \\ 1 & 0.0724 & 35.52 & 11.05 & 0.0721 & +0.3 \\ 2 & 0.0738 & 35.52 & 10.45 & 0.0739 & +0.1 \\ 3 & 0.0575 & 35.06 & 15.64 & 0.0573 & -0.2 \\ 4 & 0.0555 & 35.07 & 16.18 & 0.0553 & -0.2 \\ 5 & 0.0731 & 35.07 & 10.35 & 0.0730 & -0.1 \\ 6 & 0.0522 & 35.07 & 17.37 & 0.0522 & 0 \\ 7 & 0.0309 & 20.16 & 9.61 & 0.0311 & +0.2 \\ 8 & 00417 & 25.20 & 11.07 & 0.0417 & 0 \\ 9 & 0.0653 & 30.24 & 8.17 & 0.0651 & -0.2 \\ 10 & 0.0229 & 20.16 & 12.50 & 0.0226 & -0.3 \\ 11 & 0.0370 & 21.02 & 8.33 & 0.0366 & -0.4 \\ 12 & 0.0205 & 15.60 & 8.63 & 0.0205 & 0 \\ 13 & 0.0282 & 10.81 & 11.24 & 0.0282 & 0 \\ 14 & 0.0655 & 31.21 & 8.80 & 0.0661 & +0.4 \\ 15 & 0.0385 & 25.75 & 12.66 & 0.0385 & 0 \\ 16 & 0.0309 & 22.34 & 11.86 & 0.0309 & 0 \\ 17 & 0.0314 & 21.66 & 10.87 & 0.0319 & +0.4 \\ 18 & 0.0335 & 22.34 & 10.94 & 0.0336 & +0.1 \\ 19 & 0.0289 & 20.10 & 10.33 & 0.0288 & -0.1\end{array}$

Conclusions. -The oxidation to cobaltic hydroxide by perborate in alkaline solution is incomplete when more than $7 \mathrm{mg}$. of iron is present.

Cobaltic hydroxide may be quantitatively reduced and determined volumetrically by the following methods: (1) by potassium iodide in acid solution, but the reaction is slow and iron must be absent; (2) by an acid ferrous sulfate solution, the excess of which is titrated with permanganate; an empirical factor must be used in this case; (3) by a

13 This Journal, 44, 2223 (1922). 
strongly acid solution of stannous chloride, the excess of which is titrated with iodine, iodate, bromate or dichromate; if iron is present iodine will oxidize it quantitatively only in a neutral solution; (4) by acid titanous sulfate added to the neutralized solution, the excess of which, together with any ferrous salt formed, is titrated with permanganate.

\section{Oxidation of Cobalt in Potassium Hydrogen Carbonate Solution}

$\mathrm{Job}^{3 \mathrm{~g}}$ suggested a volumetric determination of cobalt based upon its oxidation by hydrogen peroxide in potassium bicarbonate solution to a green, trivalent compound to which he assigned the formula, $\mathrm{K}_{3} \mathrm{CoO}_{3}$. This was reduced by excess of standard ferrous pyrophosphate and the excess was titrated with permanganate. He gave few results and meager details. According to Durrant ${ }^{14}$ the cobalt compound has the structural formula. $\left(\mathrm{KCO}_{2}-\mathrm{O}\right)_{2}>\mathrm{CO}-\mathrm{O}-\mathrm{CO}<\left(\mathrm{OCO}_{2} \mathrm{~K}\right)_{2}$ and the reaction proceeds according to the equation, $4 \mathrm{KHCO}_{3}+2 \mathrm{CoCO}_{3}+\mathrm{H}_{2} \mathrm{O}_{2}=\left(\mathrm{Co}\left(\mathrm{KCO}_{3}\right)_{2}\right)_{2}$ $\mathrm{O}+2 \mathrm{CO}_{2}+2 \mathrm{H}_{2} \mathrm{O}$. The compound is stable only in the presence of a high concentration of bicarbonate, for which reason only potassium bicarbonate can be used. When heated it forms cobaltic hydroxide. The excess of peroxide seems to decompose very quickly even at room temperature, but the dissolved oxygen with perhaps traces of peroxide must be removed by passing carbon dioxide through the warm solution. This is the critical part of the method, for when the solution is too warm or the time too protracted, some decomposition occurs while, on the other hand, there is danger of not removing all of the excess of oxygen. The limits here are rather narrow and affected to some extent by the presence of other metals. It was necessary, therefore, to study carefully the effects of varying these conditions.

The following procedure was adopted.

To the slightly acid solution of cobalt $10 \mathrm{cc}$. of $3 \%$ hydrogen peroxide was added and potassium bicarbonate until a green color appeared, then $30 \mathrm{~g}$. in excess. The precipitate which formed dissolved in the excess. The solution, $150 \mathrm{cc}$. in volume, was heated to the temperature stated in the table and a rapid current of carbon dioxide was passed through it. It was cooled quickly, $5 \mathrm{~g}$. of powdered crystallized sodium pyrophosphate was added and then ferrous sulfate until a deep pink color appeared, showing reduction to cobaltous pyrophosphate. Twenty-five cc. of 1:1 sulfuric acid was added to neutralize the bicarbonate, with great care on account of the violence of the effervescence, after which the current of gas was discontinued. The excess of ferrous sulfate was then titrated with permanganate solution. The pink color of the cobalt was eliminated by adding nickel sulfate; 1 or $2 \mathrm{cc}$. of $0.05 \mathrm{~N}$ ferrous sulfate solution was added in excess; $1 \mathrm{cc}$. of $0.05 \mathrm{~N}$ solution is equivalent to $2.948 \mathrm{mg}$. of cobalt.

The effect of varying the temperature and time of heating is shown in Table IX. The weight of cobalt in each experiment varied between 38 and $65 \mathrm{mg}$.

14 Durrant, J. Chem. Soc., 87, 1781 (1905). 
Discrepancies will be observed in this table, for the method does not give quite as concordant results as does oxidation to cobaltic hydroxide; heating for 5 minutes at $63^{\circ}$, however, seems to be quite satisfactory.

TABLE IX

\begin{tabular}{|c|c|c|c|c|c|}
\hline \multicolumn{6}{|c|}{ EFFECT OF TEMPERATURE AND TIME OF HEATING } \\
\hline $\begin{array}{c}\text { Temperature } \\
{ }^{\circ} \mathrm{C} .\end{array}$ & $\begin{array}{l}\text { Time } \\
\text { of heating } \\
\text { Min. }\end{array}$ & $\begin{array}{l}\text { Error } \\
\mathrm{Mg} \text {. }\end{array}$ & $\begin{array}{c}\text { Temperature } \\
{ }^{\circ} \mathrm{C} .\end{array}$ & $\begin{array}{c}\text { Time } \\
\text { of heating } \\
\text { Min. }\end{array}$ & $\begin{array}{l}\text { Error } \\
\text { Mg. }\end{array}$ \\
\hline 85 & 20 & -1.3 & 63 & 5 & +0.1 \\
\hline 85 & 10 & -0.2 & 63 & 3 & -0.3 \\
\hline 65 & 10 & -0.8 & 63 & 1 & -0.3 \\
\hline 63 & 15 & -0.4 & 60 & 30 & 0 \\
\hline 63 & 5 & 0 & 60 & 0 & +1.2 \\
\hline 63 & 5 & +0.3 & 50 & 5 & +0.3 \\
\hline 63 & 5 & -0.2 & 43 & 5 & +1.2 \\
\hline 63 & 5 & -0.1 & 20 & 10 & +1.5 \\
\hline 63 & 5 & +0.2 & 20 & $12 \mathrm{hrs}$. & +0.7 \\
\hline
\end{tabular}

The advantage of this method lies in the fact that the interference of moderate amounts of arsenic, iron and manganese, is less than in the

TABLE X

\begin{tabular}{|c|c|c|c|c|c|c|c|}
\hline & & & FECT & DTHER & TALS & & \\
\hline & $\begin{array}{c}\text { Co } \\
\text { taken }\end{array}$ & $\begin{array}{c}\mathrm{Fe} \\
\text { added }\end{array}$ & $\begin{array}{c}\text { As } \\
\text { added }\end{array}$ & $\begin{array}{c}\mathrm{Ni} \\
\text { added }\end{array}$ & $\begin{array}{c}\mathrm{Mn} \\
\text { added }\end{array}$ & $\begin{array}{l}\text { Co } \\
\text { found }\end{array}$ & Error \\
\hline $1^{t t}$ & $\begin{array}{c}\mathrm{G} \\
0.0440\end{array}$ & $\begin{array}{c}\text { G. } \\
0.012\end{array}$ & G. & G. & $\begin{array}{l}\text { G. } \\
\ldots\end{array}$ & $\begin{array}{c}\text { G. } \\
0.0437\end{array}$ & $\begin{array}{c}\mathrm{Mg} . \\
-0.3\end{array}$ \\
\hline $2^{n}$ & 0.0772 & 0.033 & $\ldots$ & $\ldots$ & $\ldots$ & 0.0766 & -0.6 \\
\hline 3 & 0.0410 & 0.055 & $\ldots$ & $\ldots$ & $\ldots$ & 0.0397 & -1.3 \\
\hline 4 & 0.0491 & 0.055 & . & $\ldots$ & $\ldots$ & 0.0468 & -0.3 \\
\hline 5 & 0.0540 & 0.088 & $\ldots$ & $\ldots$ & $\ldots$ & 0.0536 & -0.4 \\
\hline 6 & 0.0736 & $0.099^{b}$ & $\ldots$ & $\ldots$ & $\ldots$ & 0.0731 & -0.5 \\
\hline 7 & 0.0430 & $\ldots$ & 0.140 & & . & 0.0431 & +0.1 \\
\hline 8 & 0.0607 & $\ldots$ & $\ldots$ & 0.030 & $\ldots$ & 0.0604 & -0.3 \\
\hline 9 & 0.0643 & $\ldots$ & $\ldots$ & 0.100 & $\ldots$ & 0.0639 & -0.4 \\
\hline 10 & 0.0439 & 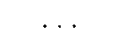 & .. & 0.200 & . & 0.0437 & -0.2 \\
\hline 11 & 0.0540 & & & 0.250 & $\ldots$ & 0.0513 & -2.7 \\
\hline 12 & 0.0575 & 0.005 & $\ldots$ & 0.250 & $\ldots$ & 0.0575 & 0 \\
\hline 13 & 0.0711 & 0.088 & $\ldots$ & 0.250 & $\ldots$ & 0.0710 & -0.1 \\
\hline 14 & 0.0531 & & 0.350 & 0.250 & $\ldots$ & 0.0331 & -20.0 \\
\hline 15 & 0.0471 & 0.055 & 0.140 & 0.250 & $\ldots$ & 0.0444 & -2.7 \\
\hline 16 & 0.0659 & 0.023 & 0.350 & 0.100 & $\ldots$ & 0.0599 & -6.0 \\
\hline 17 & 0.0470 & 0.012 & 0.140 & 0.040 & $\ldots$ & 0.0455 & -1.2 \\
\hline 18 & 0.0543 & & $\ldots$ & . & 0.012 & 0.0513 & -3.0 \\
\hline 19 & 0.0458 & 0.055 & $\ldots$ & & 0.025 & 0.0456 & -0.2 \\
\hline 20 & 0.0370 & 0.005 & $\ldots$ & & 0.006 & 0.0385 & +1.5 \\
\hline 21 & 0.0795 & 0.077 & $\ldots$ & $\ldots$ & 0.006 & 0.0796 & +0.1 \\
\hline
\end{tabular}

${ }^{a}$ Heated to $63^{\circ}$ for 5 minutes.

b $50 \mathrm{~g}$. of $\mathrm{KHCO}_{3}$ added.

other, as shown in Table $\mathrm{X}$. The effect of large amounts of iron is to decrease the maximum temperature permissible in destroying the excess of 
peroxide. The arsenic was added as arsenic acid, the other metals as sulfates. Thirty g. of potassium bicarbonate was added except when $99 \mathrm{mg}$. of iron was present, when it was increased to $50 \mathrm{~g}$. All solutions were heated to $50^{\circ}$ for 5 minutes unless otherwise noted. The results are shown in the preceding table. The effect of iron is much less with this method than in strongly alkaline solution. It is necessary to add sufficient bicarbonate to obtain a clear solution, which, if $0.1 \mathrm{~g}$. of iron is present means about $50 \mathrm{~g}$. Nickel, even in small amounts will not dissolve in excess of bicarbonate; when a little iron is also present, however, a clear solution is obtained unless the amount of nickel is very large. It is, therefore, desirable to add about $5 \mathrm{mg}$. of iron if none is present (Expts. 11 and 12); $250 \mathrm{mg}$. of nickel alone always gave low results; less than that did not introduce much of an error. It was thought that possibly the presence of the nickel precipitate caused a slight decomposition of the cobalt compound and the attempt was made to avoid this by adding pyrophosphate before or after the oxidation, but no appreciable improvement resulted. Manganese is not oxidized by peroxide in bicarbonate solution but, like nickel, is insoluble in excess of bicarbonate. Even $6 \mathrm{mg}$. caused low results. In the presence of sufficient iron, however, a clear solution resulted if not over $25 \mathrm{mg}$. was present, and accurate results were obtained. More iron is required than in the case of nickel (Expts. 1821). Arsenic alone is without effect, but in the presence of nickel the results are very low and even when iron is added the error is serious (Expts. $7,14-17)$.

Iodine may be used to titrate the excess of ferrous pyrophosphate as described in the preceding method (p. 2245) if the bicarbonate is partly neutralized. A solution of $30 \mathrm{~g}$. of potassium bicarbonate and $5 \mathrm{~g}$. of sodium pyrophosphate in a volume of $150 \mathrm{cc}$. was neutralized with 1:1 sulfuric acid until aurine added as indicator became orange; $12-15 \mathrm{cc}$. of acid gave satisfactory results, while with $17 \mathrm{cc}$. the oxidation of iron was incomplete.

A few other experiments on the titration of ferrous pyrophosphate with iodine will be recorded here because of their possible value in other reactions in which this reducing agent is used. To $30 \mathrm{cc}$. of $0.05 \mathrm{~N}$ ferrous sulfate solution were added $10 \mathrm{cc}$. of hydrochloric acid (sp. gr. 1.18), 100 cc. of water, $5 \mathrm{~g}$. of sodium pyrophosphate decahydrate and various amounts of sodium bicarbonate. Oxygen was excluded by a current of carbon dioxide. A slight excess of standard iodine solution was added, the gas current stopped and the excess of iodine titrated with standard thiosulfate solution. With $8 \mathrm{~g}$. of bicarbonate the error was $-0.06 \mathrm{cc}$. of $0.05 \mathrm{~N}$ iodine, with $10 \mathrm{~g} .,+0.06 \mathrm{cc}$. (average of 11 titrations); with $12 \mathrm{~g} .,-0.04 \mathrm{cc}$, and with $15 \mathrm{~g} .,+0.33 \mathrm{cc}$. It is evident that the amount of sodium bicarbonate can vary between 8 and $12 \mathrm{~g}$. A similar set of 
experiments was run using borax and boric acid instead of bicarbonate, except that only $5 \mathrm{cc}$. of hydrochloric acid was added. The results are shown in Table XI.

\begin{tabular}{ccccc}
\multicolumn{5}{c}{ Table XI } \\
Titration of FerRous Pyrophosphate with IodiNe \\
Borax & Boric acid & Error & Borax & No boric acid \\
added & added & $0.05 N$ iodine & added & $0.1 N$ iodine \\
G. & G. & Ce. & G. & Cc. \\
20 & 0 & -3.28 & 15 & -0.74 \\
40 & 0 & -0.20 & 25 & -0.84 \\
45 & 0 & -0.04 & 30 & -0.37 \\
50 & 0 & -0.06 & 35 & -0.12 \\
30 & 2 & -0.03 & 40 & -0.08 \\
30 & 5 & -0.16 & 45 & +0.03 \\
30 & 10 & -0.49 & 50 & +0.30
\end{tabular}

About $45 \mathrm{~g}$. of borax is the proper amount. On account of the quickness with which it dissolves, bicarbonate is somewhat more satisfactory.

Conclusions.-Although cobalt is completely oxidized by hydrogen peroxide in bicarbonate solution the compound is not very stable and care must be used in removing the excess of peroxide before reduction with ferrous pyrophosphate.

Moderate amounts of iron, nickel and arsenic do not interfere when present separately, but low results are obtained when all three or the two latter are present. Manganese is not oxidized and in small amounts does not interfere if sufficient iron is present. In general, the presence of a small amount of iron is desirable.

\section{Determination of Cobalt in Steel}

The methods described in this paper were applied to the determination of cobalt in alloy steels. Samples weighing $0.7 \mathrm{~g}$. were treated with 40 cc. of hydrochloric acid (sp. gr. 1.1). The tungsten separated as a black powder. One or $2 \mathrm{cc}$. of $85 \%$ phosphoric acid and $3 \mathrm{cc}$. of nitric acid were added slowly and the solution was kept hot until everything was dissolved. Seven $g$. of citric acid was added, then conc. ammonia until the solution was alkaline and finally $6 \mathrm{cc}$. in excess. To the hot alkaline solution was added with constant stirring $1 \mathrm{~g}$. of phenyl-thiohydantoic acid dissolved in $30 \mathrm{cc}$. of hot water. The cobalt precipitated at once, and the solution was boiled for a few minutes with vigorous stirring to prevent bumping. It required longer than usual to obtain complete precipitation, and this was facilitated by agitating the solution. In all cases, the filtrates were found to be free from cobalt. The precipitate was dried, ignited, fused with potassium pyrosulfate and dissolved in water. In Sample A the cobalt was oxidized with perborate and reduced with stannous chloride, the excess of which was titrated with dichromate. In Sample B (British 
Standard Cr V W Co. Steel "W") the cobalt was oxidized in bicarbonate solution and reduced with ferrous pyrophosphate, the excess of which was titrated with permanganate solution. Sample A was precipitated twice, although this was not necessary. The results are given in Table XIJ.

TABLE XII

\begin{tabular}{|c|c|c|}
\hline \multicolumn{3}{|c|}{ Determination of CoBalt in Alloy Steels } \\
\hline & Co found $\%$ & Co present $\%$ \\
\hline & $(3.77)$ & \\
\hline Cr V W Co. & 3.75 & \\
\hline Steel A & 3.74 & $3.84^{a}$ \\
\hline & 3.75 & \\
\hline Cr V W Co. & 4.88 & 478 \\
\hline Steel B & 4.91 & $4.60^{\circ}$ \\
\hline
\end{tabular}

${ }^{a}$ Value obtained by works chemist who precipitated cobalt with nitroso- $\beta$-naph thol after removal of tungsten and iron and weighed as $\mathrm{Co}_{3} \mathrm{O}_{4}$.

${ }^{b}$ Certificate value. Results of individual analysts varied from 4.53 to 4.99 .

\section{Summary}

1. For the determination of cobalt, volumetric methods are in general the most accurate and satisfactory.

2. The most accurate method involves the oxidation of cobalt to cobaltic hydroxide in strongly alkaline solution by means of perborate or hydrogen peroxide, followed by its volumetric reduction to a cobaltous salt. This reduction may be accomplished by the following methods.

(a) By potassium iodide in acid solution, the iodine liberated being titrated with thiosulfate; iron must be absent.

(b) By adding the cobaltic hydroxide to an acid ferrous sulfate solution, the excess of which is titrated with permanganate solution. An empirical factor must be used.

(c) By a strongly acid solution of stannous chloride, the excess of which is titrated with iodine, iodate, bromate or dichromate solution. The last, titrated electrometrically, is especially recommended. If iron is present, iodine will oxidize it quantitatively only in a neutral solution.

(d) By titanous sulfate, the excess of which is titrated with permanganate. Since titanous hydroxide decomposes water with liberation of hydrogen, the alkaline solution must first be almost completely neutralized by one of several methods suggested.

3. Nickel does not interfere, but the oxidation is incomplete when more than $7 \mathrm{mg}$. of iron is present.

4. In the presence of a large excess of potassium bicarbonate, cobalt is oxidized by hydrogen peroxide to a green, trivalent compound, which is reduced in the presence of pyrophosphate by ferrous sulfate, the excess of which is titrated with permanganate after acidifying with sulfuric acid.

5. Iron and manganese in small amounts do not interfere in this method, 
but the principal source of error is in the removal of excess peroxide without decomposing the cobalt compound.

6. Cobalt in alloy steels was determined volumetrically after separation by phenyl-thiohydantoic acid.

ANN ARBOR, Michigan

[CONTRIBUTION HROM THE CHEMICAL, LABORATORY OF THE UNIVERSITY OF MICHIGAN]

\section{THE SEPARATION OF COPPER BY MEANS OF PHENYL- THIOHYDANTOIC ACID ${ }^{1}$}

By H. H. WIILARD aNd DOROTHY HaLL

Received July 28, 1922

During the course of an investigation on the separation of cobalt by means of phenyl-thiohydantoic acid ${ }^{2}$ it was found that in a solution slightly acid with acetic acid, copper, lead, mercury, cadmium, bismuth and antimony are quantitatively precipitated by this reagent, while tin, arsenic and the metals not in the hydrogen sulfide group are not precipitated under these conditions. The bismuth and antimony compounds are soluble in alcohol. The present paper gives the details of the separation of copper by this means.

When pure, the precipitate is bright yellow, but it decomposes so readily to form sulfide that it is usually a dirty yellow. It is, therefore, impossible to weigh the copper in this form. When ignited to oxide, the latter contained sufficient sulfate to cause an error varying from +0.1 to $+0.6 \mathrm{mg}$. It was found desirable, therefore, to dissolve this oxide, preferably by fusion with potassium pyrosulfate, and to determine the copper by any of the wellknown methods.

\section{Procedure}

The solution is neutralized with ammonia and $5 \mathrm{cc}$. of glacial acetic acid added. If metals precipitated by ammonia are present, $7 \mathrm{~g}$. of citric acid is first added for every gram of metal. To the boiling solution, 300-400 cc. in volume, is added $0.5 \mathrm{~g}$. of phenyl-thiohydantoic acid dissolved in a little hot water, then dil. ammonium hydroxide until a yellow precipitate just begins to form. It is well at this point to discontinue the addition of ammonia and to boil the solution for a few minutes. If the copper is all precipitated, the yellow precipitate separates at the top leaving a clear solution. If this does not occur, more aqueous ammonia should be added; too much causes appreciable solubility of the precipitate. It also turns brown from the formation of sulfide. Precipitation is complete at once. The solution is filtered hot and the precipitate washed with hot water.

1 From a dissertation presented by Dorothy Hall in partial fulfilment of the requirements for the degree of Doctor of Philosophy.

2 This Journal, 44, 2219 (1922). 